\title{
AN INTERESTING CASE OF LEFT DIAPHRAGM RUPTURE WITH INTRATHORACIC MIGRATION OF RUPTURE SPLEEN, STOMACH \& SPLENIC FLEXOR COLON
}

Suresh Rathi ${ }^{1}$

\section{HOW TO CITE THIS ARTICLE:}

Suresh Rathi. "An interesting case of Left Diaphragm Rupture with Intrathoracic Migration of Rupture Spleen, Stomach \& Splenic Flexor Colon".Journal of Evolution of Medical and Dental Sciences 2014; Vol. 3, Issue 02, January 13; Page: 261-265, DOI:10.14260/jemds/2014/1819

ABSTRACT: Diaphragmatic rupture is a tear of diaphragm. It results from blunt or penetrating injury to trunk ${ }^{1}$. It occurs in $5 \%$ of cases of severe blunt trauma to trunk ${ }^{2}$. Mortality from traumatic rupture diaphragm is $14-50 \%{ }^{3}$. This increases to $77 \%$ when associated with shock \& head injury ${ }^{3}$. Associated injury makes the outcome worst. Here is a case with spleen tear associated with traumatic rupture of diaphragm.It migrated in left thoracic cavity causing haemothorax.

Synonym: TDR - Traumatic Diaphragmatic Rupture.

INTRODUCTION: Diaphragmatic rupture occurs in 5\% cases of severe blunt trauma to trunk 2. Injury to diaphragm is usually associated with other injuries. The Outcome depends on associated injuries then on diaphragmatic injury itself 4 . Left diaphragmatic injuries are four times more common than right ${ }^{5}$. Bilateral cases are rare- $5-8 \%$ only ${ }^{5}$. Since the pressure in abdominal cavity is higher than the chest cavity, rupture of diaphragm is always associated with migration of abdominal organs into the chest cavity. It is called acquired diaphragmatic hernia ${ }^{4}$. This migration can interfere with breathing and blood supply can be cut off to organs that herniate through tear, damaging them. Spleen herniation through rupture is rare, still uncommon is a ruptured spleen herniating through the defect, causing haemothorax. Injuries occurring on the right are associated with higher rate of death and more numerous and serious accompanying injuries ${ }^{6}$.

CASE REPORT: A 52 year old male presented following road traffic accident. He was investigated \& diagnosed as rupture diaphragm on X-ray \& CT-Scan at other Hospital. He was transferred to us after three days of accident. He was pale, breathless and febrile at time of admission. Air entry on left side was nil. He had fractured 8th, 9th 10th, 11th \& 12th rib on left side \& displaced fracture left iliac bone. He had bruised marks on left loin \& pelvis. Abdomen was soft with minimal tenderness. Bowel sounds were present.

His investigation reports which were done in the previous hospital were as follows: HB 12gm, WBC - 13300, Platelets - 2.4lacs, Random blood sugar - 128mg, Blood urea - 59, Serum creatinine - 1.1, S Electrolytes were normal.

X-ray chest and CT-Scan showed herniation of splenic flexor colon, stomach, omentum\& spleen in left pleural cavity with haemothorax.

He was transferred to our hospital after 3 days of the accident. His HB had dropped to 8 gms on arrival at our hospital. $\mathrm{pO}_{2}$ was $84 \%$. Rest of the reports were normal.

He was given proper antibiotics, fluids \& blood preoperatively.

He was taken to the operation theatre. Abdomen was opened through left subcostal incision under G A. There was a large tear in mid posterior part of left dome of diaphragm. Part of stomach, 
omentum, splenic flexor of colon \& spleen went in left pleural cavity. It was full of blood with rupture spleen. Abdominal organs were retrieved into abdominal cavity. Splenectomy was done. Intercostal drainage was done under vision. Diaphragm was repaired with loop nylon in 2 layers. Peritoneal lavage was done. Abdomen closed with a drain in peritoneal cavity. Patient made good post operative recovery.

Oral fluids started on 3rd Post operative day. Abdominal drain removed on 3rd post operative day. Chest drain removed on 5th day. Pneumococcal vaccine was given. He was discharged on 6th post operative day.

DISCUSSION: In 1579, Ambrose Pare made first description of diaphragm rupture in a French artillery captain who had been shot eight months before his death from complication of rupture ${ }^{7}$. Using autopsy, Pare also described diaphragmatic rupture in people who suffered blunt \& penetrating trauma ${ }^{7}$. Reports of rupture date back at least as far as 17 th century. Petit was 1 st to establish the difference between acquired and congenital diaphragmatic hernia. In 1888 Neumann repaired a hernia of the stomach into left chest that was caused by trauma ${ }^{7}$.

I presented this case because of rare to have rupture spleen migrating intothoracic cavity. Commonly herniated organs are stomach, small \& large bowel, spleen, liver and lastly kidney. In our case stomach, omentum, splenic flexure of colon \& rupture spleen migrated in thorax. Since the pressure in abdominal cavity is higher than the chest cavity, rupture of diaphragm is always associated with herniation of abdominal organs into chest cavity. It is called traumatic diaphragmatic hernia ${ }^{4}$. This herniation can interfere with breathing, reduction in cardiac output \& blood supply can be cut off to organs that herniate through tear, damaging them. Failure to diagnose traumatic rupture diaphragm on plain film ranges from $12-66 \%{ }^{8}$. Concurrent pulmonary contusion $\&$ atelectasis can mimic or mast TDR on plain chest film ${ }^{8}$. Plain film sensitivity for detection ranges from $27-60 \%$ for left-sided hernias and $17-33 \%$ for right. Most common specific radiological finding of TDR include intra-thoracic herniation of hollow viscera (small bowel, stomach, or colon), and identification of nasogastric tube above level of left hemidiaphragm ${ }^{9}$. A herniation at costophrenic angle may be misdiagnosed as a pleural effusion or haemothorax on initial $\mathrm{x}$ ray chest $\&$ a thoracic drainage tube could accidently be placed into herniated organs ${ }^{8}$. Multidetector CT (MDCT) has TDR detection rate of $73-92 \%{ }^{10}$. It is gold standard for diagnosis ${ }^{10}$. CT is advantageous in evaluation of other associated injuries.

CT findings of TDR - Diaphragm discontinuity. Dangling diaphragm sign. - 73\% sensitivity, $90 \%$ specificity 11.

Intrathoracic herniation of abdominal contents - 58\% sensitivity, $100 \%$ specificity 11 .

Collar sign- constriction of herniated viscera - $67 \%$ sensitivity, $100 \%$ specificity ${ }^{11}$.

Dependent viscera sign - visualization of herniated viscera against the posterior wall - 100\% sensitivity \& $90 \%$ specificity ${ }^{12}$.

Urgent operation is needed after diagnosis. 


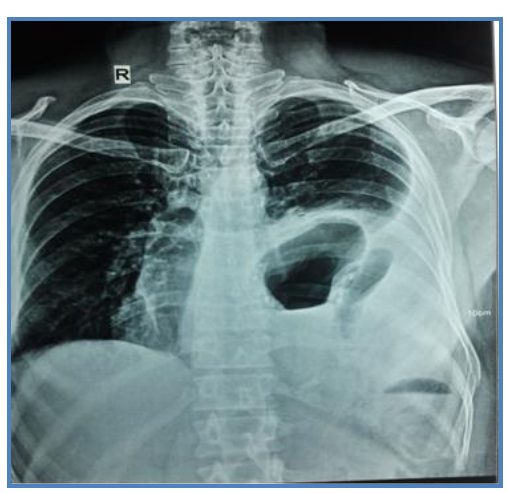

Fig. 1: X-ray chest

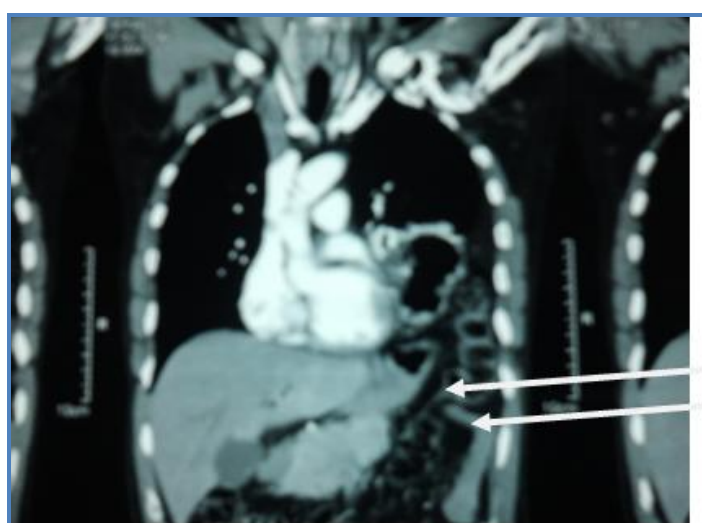

Splenic flexor colon Diaphragm

Fig. 2: CT Scan showing migration of splenic flexor colon in chest

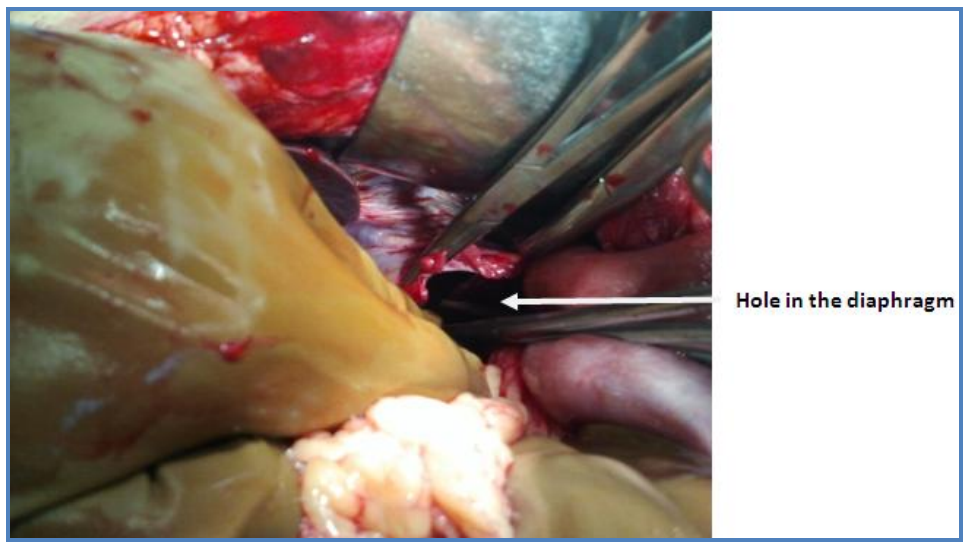

Fig. 3: Hole in the Diaphragm 


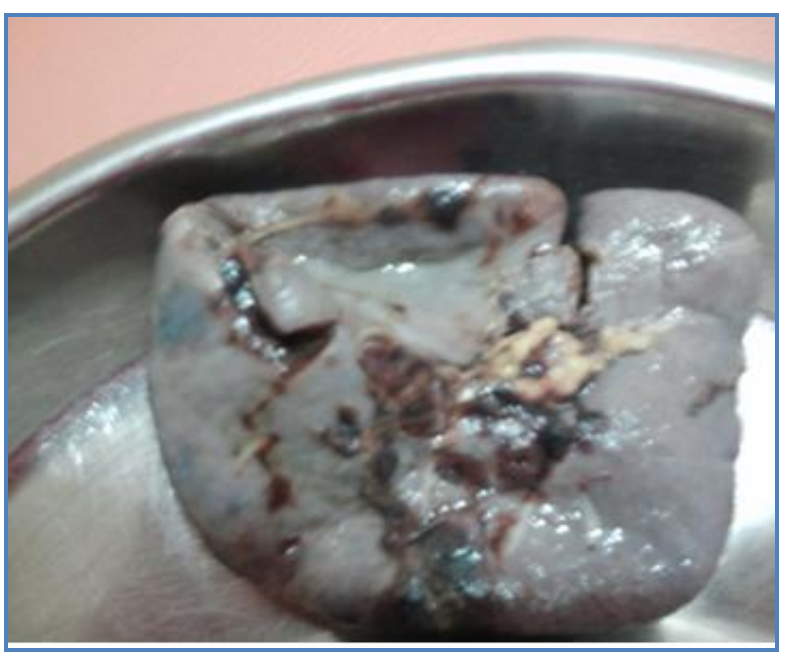

Fig. 4: Rupture Spleen

\section{REFERENCES:}

1. Sliker CW. "Imaging of diaphragm injuries". Radiol Clin North Am; March 2006: 44 (2).

2. Nolan JP. "Major trauma". In Adams AP, Cashman JN, Grounds RM. Recent Advances in Anaesthesia and Intensive Care, 2002: Volume 22. London: Greenwich Medical Media. p. 182.

3. Sangster G, Ventura V, Cabo A et Al. "Diaphragmatic rupture: frequently missed injury in blunt thoracoabdominal trauma patients". Am Soc Emergency Radiol 2007; 13 (5):225-30.

4. Scharff JR, Naunheim KS. "Traumatic diaphragmatic injuries". Thorac Surg Clin, February 2007; 17 (1): 81-5.

5. Eren S, Kantarci M, Okur A. "Imaging of diaphragmatic rupture after trauma." Ciln Radiol 2006;(6):467-77.

6. Fleisher GR, Ludwig S, Henretig FM, Ruddy RM, Silverman BK. "Thoracic trauma". Textbook of Pediatric Emergency Medicine. Hagerstown, MD: Lippincott Williams \& Wilkins. 2006.

7. Asensio JA, Petrone P, Demitriades D, commentary by Davis JW. "Injury to the diaphragm". In Moore EE, Feliciano DV, Mattox KL. Trauma. Fifth Edition. McGraw-Hill Professional. 2003; pp. 613-616.

8. Shapiro MJ Heidberg E, Durham RM, et al. "The unreliability of CT scans and initial chest radiographs in evaluating blunt trauma induced diaphragmatic rupture". Clin Radiol 1996;51:27-30.

9. Gelman R, Mirvis SE, Gens D. “Diaphragmatic Rupture Due to blunt Trauma: sensitivity of plain chest radiograph”. Ajr1991; 156: 51-57.

10. Nchimi A, Szapiro D, GhayeB, et al. "Helical CT of blunt diaphragmatic rupture". AJR 2005; 184:24-30.

11. Deser TS Edwards B, Hunt S et al. "The dependent viscera sign in CT diagnosis of blunt traumatic diaphragmatic rupture". Emerg Radiol 2010; 17(1): 37-44.

12. Bergin D, Ennis R, Keogh C, et al. "The dependent viscera sign in CT diagnosis of blunt traumatic diaphragmatic rupture". AJR 2001; 177: 1137-1140. 
AUTHORS:

1. Suresh Rathi

\section{PARTICULARS OF CONTRIBUTORS:}

1. Consultant Surgeon, Department of General Surgery, Medisquare Hospital, Indore, India.

\section{NAME ADDRESS EMAIL ID OF THE} CORRESPONDING AUTHOR:

Dr.Suresh Rathi,

69, Anand Nagar,

Behind Sapna-Sangita,

Indore (M.P.), India.

Email-sureshuro@rediffmail.com

Date of Submission: 19/12/2013.

Date of Peer Review: 20/12/2013.

Date of Acceptance: 26/12/2013.

Date of Publishing: 08/01/2014 